\title{
Non-invasive or minimally invasive autopsy compared to conventional autopsy of suspected natural deaths in adults: a systematic review
}

\author{
Britt M. Blokker ${ }^{1,2,3}$ - Ivo M. Wagensveld ${ }^{1,2,3}$ • Annick C. Weustink ${ }^{2}$. \\ J. Wolter Oosterhuis ${ }^{1,2}$ • M. G. Myriam Hunink ${ }^{2,3,4}$
}

Received: 30 January 2015 / Revised: 16 June 2015 / Accepted: 29 June 2015 /Published online: 27 July 2015

(C) The Author(s) 2015. This article is published with open access at Springerlink.com

\begin{abstract}
Objectives Autopsies are used for healthcare quality control and improving medical knowledge. Because autopsy rates are declining worldwide, various non-invasive or minimally invasive autopsy methods are now being developed. To investigate whether these might replace the invasive autopsies conventionally performed in naturally deceased adults, we systematically reviewed original prospective validation studies.

Materials and methods We searched six databases. Two reviewers independently selected articles and extracted data. Methods and patient groups were too heterogeneous for meaningful meta-analysis of outcomes.

Results Sixteen of 1538 articles met our inclusion criteria. Eight studies used a blinded comparison; ten included less than 30 appropriate cases. Thirteen studies used radiological imaging (seven dealt solely with non-invasive procedures), two thoracoscopy and laparoscopy, and one sampling without imaging. Combining $\mathrm{CT}$ and MR was the best non-invasive method (agreement for cause of death: $70 \%, 95 \%$ CI: 62.6;
\end{abstract}

M. G. Myriam Hunink

m.hunink@erasmusmc.nl

1 Department of Pathology, Erasmus University Medical Centre, Rotterdam, The Netherlands

2 Department of Radiology, Erasmus University Medical Centre, Rotterdam, The Netherlands

3 Department of Clinical Epidemiology, Erasmus University Medical Centre, Room Na-2818, P.O. Box 2040, 3000

CA Rotterdam, The Netherlands

4 Centre for Health Decision Sciences, Harvard T.H. Chan School of Public Health, Harvard University, Boston, MA, USA
76.4), but minimally invasive methods surpassed noninvasive methods. The highest sensitivity for cause of death (90.9 \%, 95\%CI: 74.5; 97.6, suspected duplicates excluded) was achieved in recent studies combining CT, CTangiography and biopsies.

Conclusion Minimally invasive autopsies including biopsies performed best. To establish a feasible alternative to conventional autopsy and to increase consent to post-mortem investigations, further research in larger study groups is needed.

Key points

- Health care quality control benefits from clinical feedback provided by (alternative) autopsies.

- So far, sixteen studies investigated alternative autopsy methods for naturally deceased adults.

- Thirteen studies used radiological imaging modalities, eight tissue biopsies, and three CT-angiography.

- Combined CT, CT-angiography and biopsies were most sensitive diagnosing cause of death.

Keywords Systematic review - Alternative clinical autopsy · Post-mortem imaging $\cdot$ Post-mortem biopsies $\cdot$ Validation studies

$\begin{array}{ll}\text { Abbreviations } \\ \text { CA } & \text { Conventional Autopsy } \\ \text { COD } & \text { Cause Of Death } \\ \text { CTA } & \text { CT-Angiography } \\ \text { DE } & \text { Dual Echo } \\ \text { FLAIR } & \text { Fluid-Attenuated Inversion Recovery } \\ \text { FFE } & \text { Fast Field Echo } \\ \text { FSE } & \text { Fast Spin Echo } \\ \text { G } & \text { Gauge } \\ \text { GE } & \text { Gradient Echo } \\ \text { IR } & \text { Inversion Recovery }\end{array}$




$\begin{array}{ll}\text { (MD)CT } & \text { (Multi Detector) Computed Tomography } \\ \text { MR(I) } & \text { Magnetic Resonance (Imaging) } \\ \text { N } & \text { Number } \\ \text { n/r } & \text { not reported } \\ \text { PMI } & \text { Post-Mortem Interval } \\ \text { PRISMA } & \begin{array}{l}\text { Preferred Reporting items for Systematic Re- } \\ \text { views and Meta-Analyses }\end{array} \\ \text { SE } & \text { Spin Echo } \\ \text { SPIR } & \text { Spectral Presaturation with Inversion Recovery } \\ \text { TSE } & \text { Turbo Spin Echo } \\ \text { WHO } & \text { World Health Organization }\end{array}$

\section{Introduction}

\section{Current problem and background}

Autopsy is an age-old method for identifying the underlying pathology leading to death, and/ or for detecting unnatural deaths. It is an important tool for both criminal investigations and for health care quality control. In clinical practice, autopsy contributes to medical knowledge, medical training, accurate mortality statistics, epidemiologic databases, and therapeutic and diagnostic improvements [1-3].

Despite continuing development of innovative new diagnostic techniques, there are substantial discrepancies between ante-mortem and post-mortem diagnoses [4-11]. Hence, an autopsy continues to provide medical professionals with valuable feedback on provided care and possibly new insights for future decision-making. In some cases it also leads to counselling advice for family members.

Clinical autopsy rates are rapidly declining worldwide [12-14]. To perform clinical autopsies, consent from next of kin is obligatory in most countries. Unfortunately, consent may not be requested or recommended by physicians (who are often junior staff members) and is often refused by bereaved families [15-25]. Public resistance to autopsies has increased over the years, due to negative press attention [26], funeral delay, religious or cultural beliefs, and fear of mutilation of the deceased's body. For the latter reason, non-invasive or minimally invasive autopsy methods, which were already implemented in forensic medicine, are currently being developed to substitute clinically invasive autopsies $[12,13,26]$.

Over the last decades, MR imaging has been introduced in clinical medicine for perinatal and neonatal autopsy [27, 28]. Many other clinically established imaging techniques have emerged for broad post-mortem use in forensic medicine. Among these are image-guided tissue biopsies, and CT- or MR- angiography [29-34]. Forensic specialists have optimized them for postmortem settings. However, despite high diagnostic performance in that field, hardly any of the new post-mortem techniques have been implemented in clinical medicine.

\section{Purpose}

In this systematic review we investigate whether non-invasive or minimally invasive autopsy methods could replace conventional autopsy in adults with a suspected natural cause of death. We calculate the sensitivity and agreement of noninvasive and minimally invasive autopsy methods using conventional autopsy as a reference standard, and discuss if any method may be appropriate for a clinical setting.

\section{Materials and methods}

For this systematic review the methods of Cochrane and PRISMA were used to the extent possible [35, 36].

\section{Database search}

Together with a biomedical information specialist we searched the Embase, Medline, Web of Science and Cochrane databases. We defined search terms for Embase and, from those, we derived search terms for the other databases. The search terms included the following elements: autopsy, imaging, cause of death, and validation (see Appendix 1). Case reports, studies on children, and animal studies were excluded. The search was performed on the 16 July 2013 and, to see if any eligible articles had been published since the previous searches, it was repeated on the 1 April 2014 and on 27 June 2014. The second and third time we also searched PubMed publisher and Google Scholar. EndNote software was used to collect all articles matching the search terms and to remove duplicate records of the same study.

\section{Article selection}

The following inclusion criteria were used for article selection: (1) original prospective studies comparing the diagnostic performance of non-invasive or minimally invasive autopsy methods to that of the reference standard (conventional autopsy, not necessarily including brain autopsy); (2) outcomes defined in agreement and/or sensitivity and/or specificity of cause of death and/or detected overall, major and/or minor diagnostic findings; (3) the alternative autopsy methods covered at least an investigation of the deceased's thorax and abdomen; (4) more than five adult cases ( $\geq 18$ years of age) were studied; and (5) more than five presumed natural deaths were studied.

Two reviewers excluded the articles outside the scope of this review, based on the article titles and abstracts. Subsequently, they retrieved and evaluated the available full texts of the remaining articles and selected the articles that fully met the five inclusion criteria. A third reviewer was consulted in case the two reviewers disagreed on study eligibility. 


\section{Data extraction and analysis}

Four reviewers were involved in the analyses, of which two were already for decades involved in research and scientific publication. Two reviewers independently performed the data extraction. Their interpretation was different with respect to one or two minor data points per table and these differences could easily be resolved. A third reviewer was consulted for advice on structuring the data extraction tables. Per article, the reviewers extracted data on study population, number of cases eligible for this review, study design/ methods, cost of the methods, and, if possible, data for outcomes in $2 \times 2$ tables. From these $2 \times 2$ tables on cause of death and/or (overall, major and/or minor) diagnostic findings, both reviewers independently calculated the percentage of agreement, the sensitivity and, if possible, the specificity. If they were not able to extract any false positives and/ or true negatives, the reviewers only calculated sensitivity. If the reviewers could not extract any data from the original article for a $2 \times 2$ table, the reported outcome measures were quoted.

If necessary, the reviewers contacted the authors, requesting additional information in order to exclude individual cases (based on age or suspected forensic cause of death)
Fig. 1 a Flowchart article selection: Initial literature search. b Flowchart article selection: Second literature search. c Flowchart article selection: Third literature search

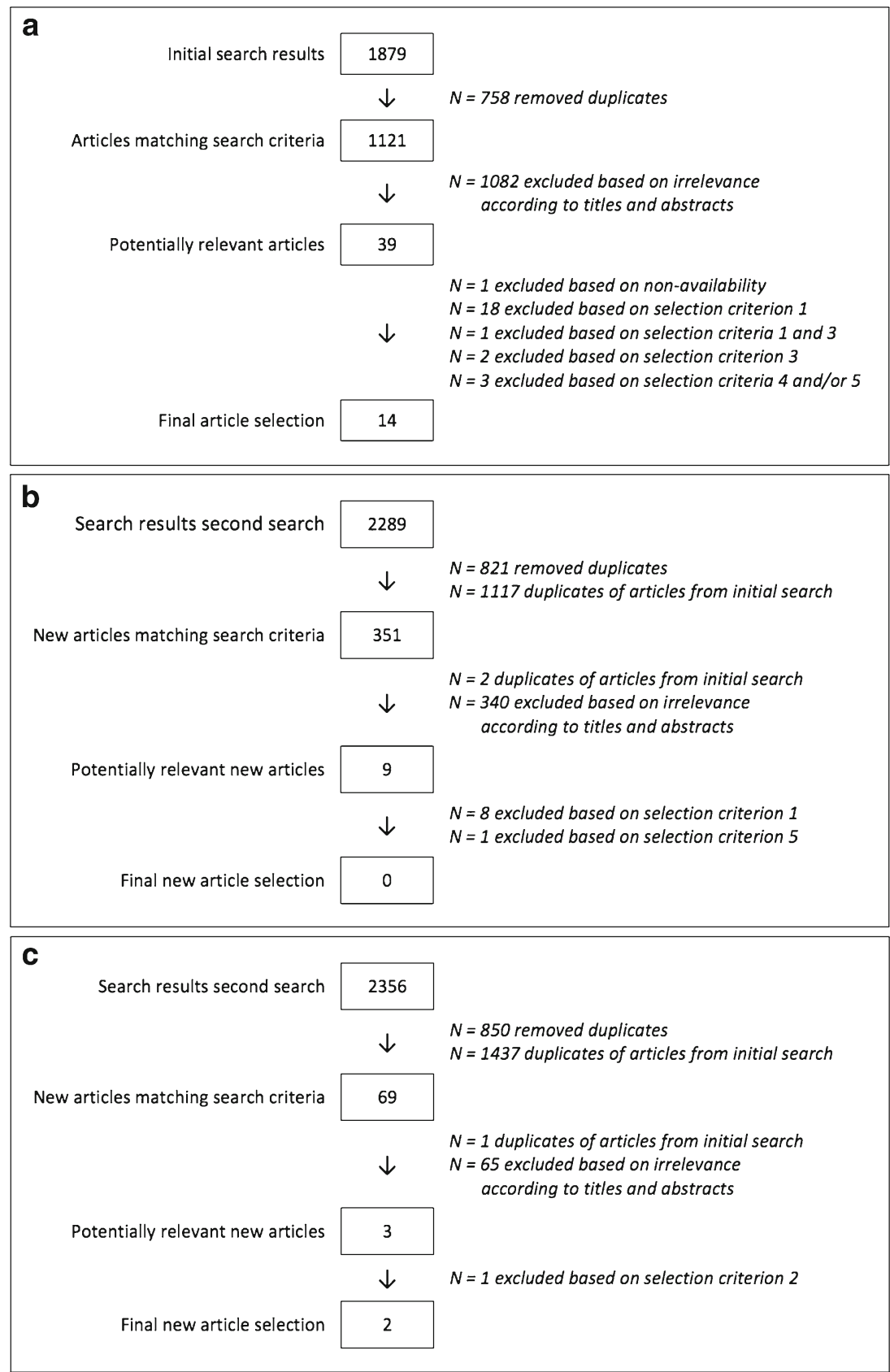


in the articles [37-42], or to identify multiple reports of the same cases [40, 41, 43, 44]. Unfortunately, only one author responded [39].

The alternative autopsy methods applied and the case characteristics in the included studies were very heterogeneous, precluding meaningful meta-analysis of the study outcomes.

The outcomes of only two studies were pooled, since these studies seemed to be performed by the same research group, investigating the same alternative autopsy method, and even including some of the same cases [43, 44].

\section{Results}

All database searches together provided us with 1538 articles that matched the search criteria (see Fig. 1), of which 51 were considered potentially relevant (see Appendix 2). One of these articles could not be obtained via our hospital library. Of the remaining 50 articles, 34 were not eligible for this systematic review upon reading the full text.

\section{Study design and quality appraisal}

Sixteen articles, published from 1996 to 2014, met the five inclusion criteria (see Tables 1, 2 and 3). Eight studies included just cases of adult deaths [37, 46-52], and in seven studies the cases were only included if the cause of death was suspected to be natural $[39,42,44,45,47,48,50]$. Among the studies that registered a male-female ratio, the majority of cases were male. The available mean ages differed from 22.7 years to 74.0 years.

Seven studies examined the accuracy of non-invasive autopsy methods, and nine studies the accuracy of various minimally invasive methods. In twelve studies a conventional autopsy (reference standard) was performed on all cases within the examined group [37, 40-45, 47-51]. In only eight studies the description of the comparison between new method and reference standard could be interpreted as blinded [40, 41, 45-50].

Complete $2 \times 2$ tables for cause of death were extracted from two articles [38, 42], for overall findings from another article [50], and for new major findings and cultures from yet another article [42]. In addition, partial $2 \times 2$ tables could be extracted from eleven studies [39-41, 43-49, 51].

For each available agreement percentage and sensitivity for cause of death in Table 3, we calculated the exact binomial confidence interval. We plotted these confidence intervals in forest plots (see Fig. 2). They were often very wide, due to small study groups.

We plotted both agreement and sensitivity in a funnel plot (see Fig. 3), and could not detect any signs of publication bias.
Agreement and accuracy of non-invasive autopsy methods

As a potential alternative to the conventional autopsy, the earliest two studies examined the use of magnetic resonance imaging (MRI) [47, 48].

Three other studies used (multi detector) computed tomography, (MD) CT [38, 39, 46].

The two most recent studies performed both MRI and CT $[37,45]$, but only one of them combined the results to define a cause of death [37]. This latter study included more cases than all other non-invasive studies together.

The results of these studies, except Puranik et al. [45], suggest that the non-invasive autopsies using CT perform somewhat better than those using MRI. The highest sensitivity achieved with CT was $70.8 \%$ [39]. The one study combining MRI and $\mathrm{CT}$ achieved an agreement of $70 \%$ in cause of death [37].

Other outcomes, such as sensitivity for major findings, could only be extracted from three studies. These outcomes could not be compared, due to the heterogeneity in study methods.

The criteria for case selection were various, and studies with similar patient groups investigated different imaging methods.

\section{Agreement and accuracy of minimally invasive autopsy methods}

The oldest minimally invasive autopsy study applied a combination of tissue biopsies and post-mortem cultures, without any kind of imaging and showed an agreement and sensitivity of (almost) $60 \%$ for the cause of death [42]. They also showed a reasonably good agreement and sensitivity for new major findings.

Two studies performing a combination of post-mortem laparoscopy, thoracoscopy and (if indicated) tissue biopsies showed very high agreement percentages for the cause of death $[51,52]$. However, one of these studies included very few cases $(n=7)$ and the other selected cases to maximize the benefit of the studied method.

There were two studies, by the same author, examining ultrasound and (ultrasound-guided) biopsies in comparison to autopsy [40, 41]. It is unknown if any of their cases were reported twice. The second study appeared to have worse outcomes than the first, but the agreement was still higher than in all non-invasive methods.

Weustink et al. [50] evaluated a combination of MRI and CT, and ultrasound-guided tissue biopsies, and showed agreement for cause of death in $76.7 \%$. They were the only investigators who calculated specificity for overall findings, which was $99 \%$.

In their most recent study, Wichmann et al. performed native CT and multiphase CT-angiography (no tissue biopsies) [49]. With the addition of the CT-angiography, the sensitivity of new major diagnoses had improved from $71.4 \%$ (MDCT only) to $92.9 \%$. 


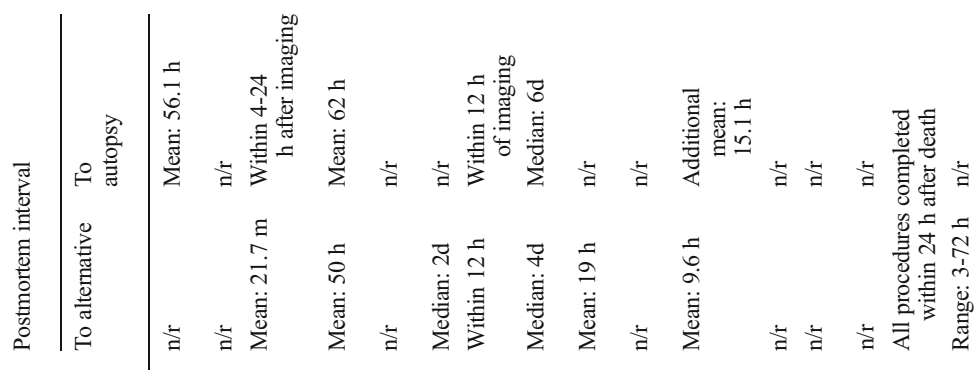

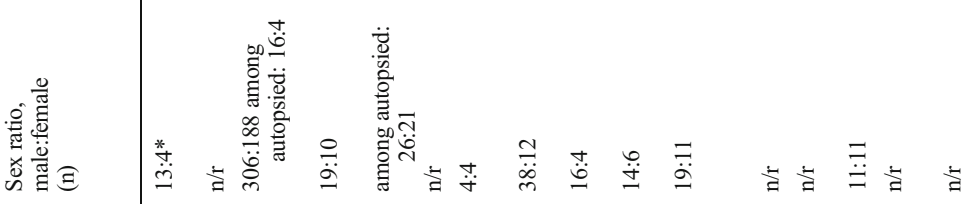

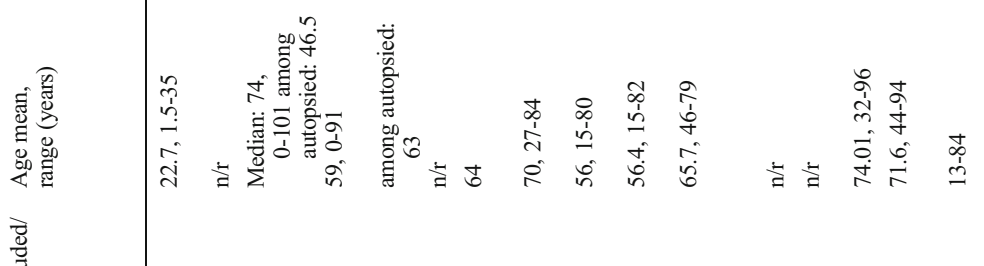

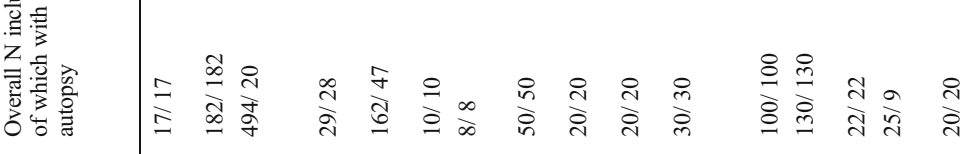

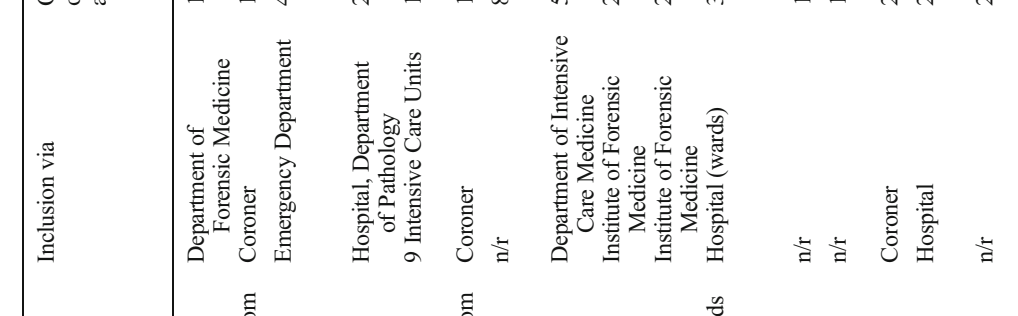

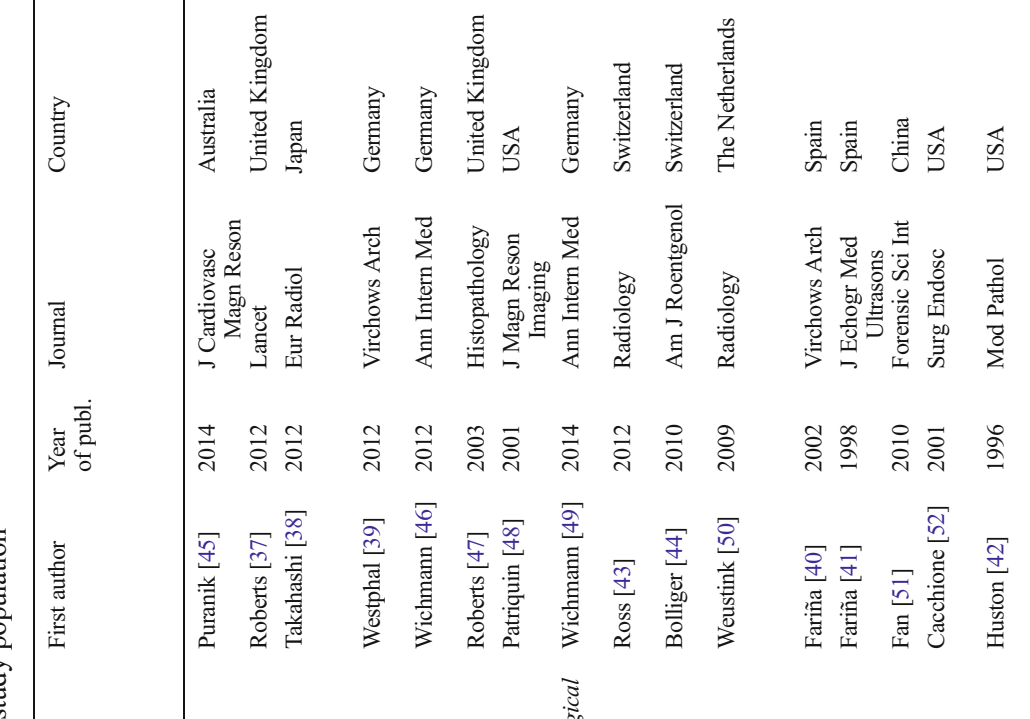

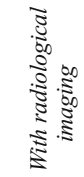

范

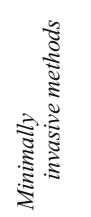

竞

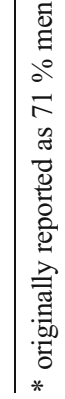




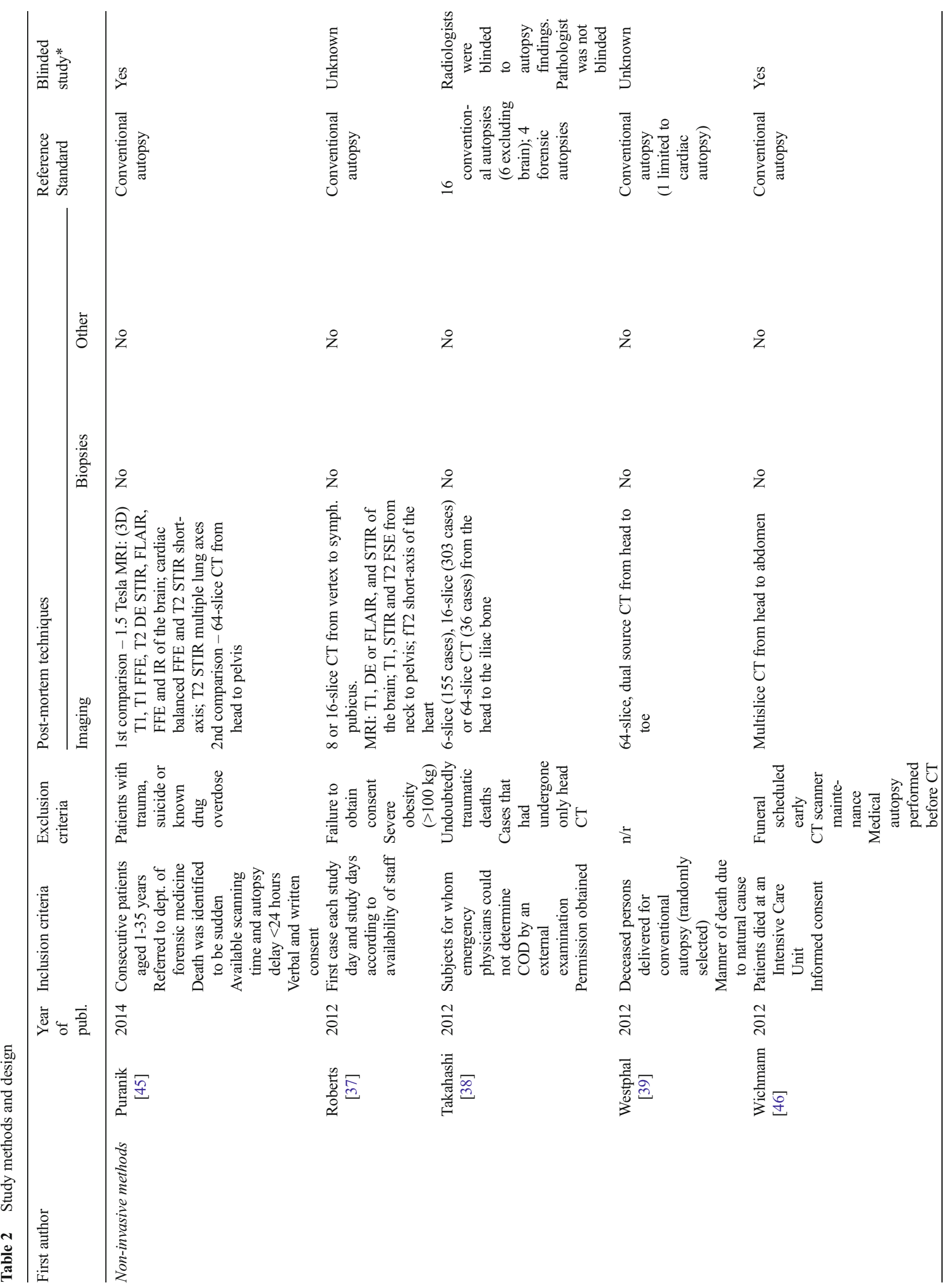




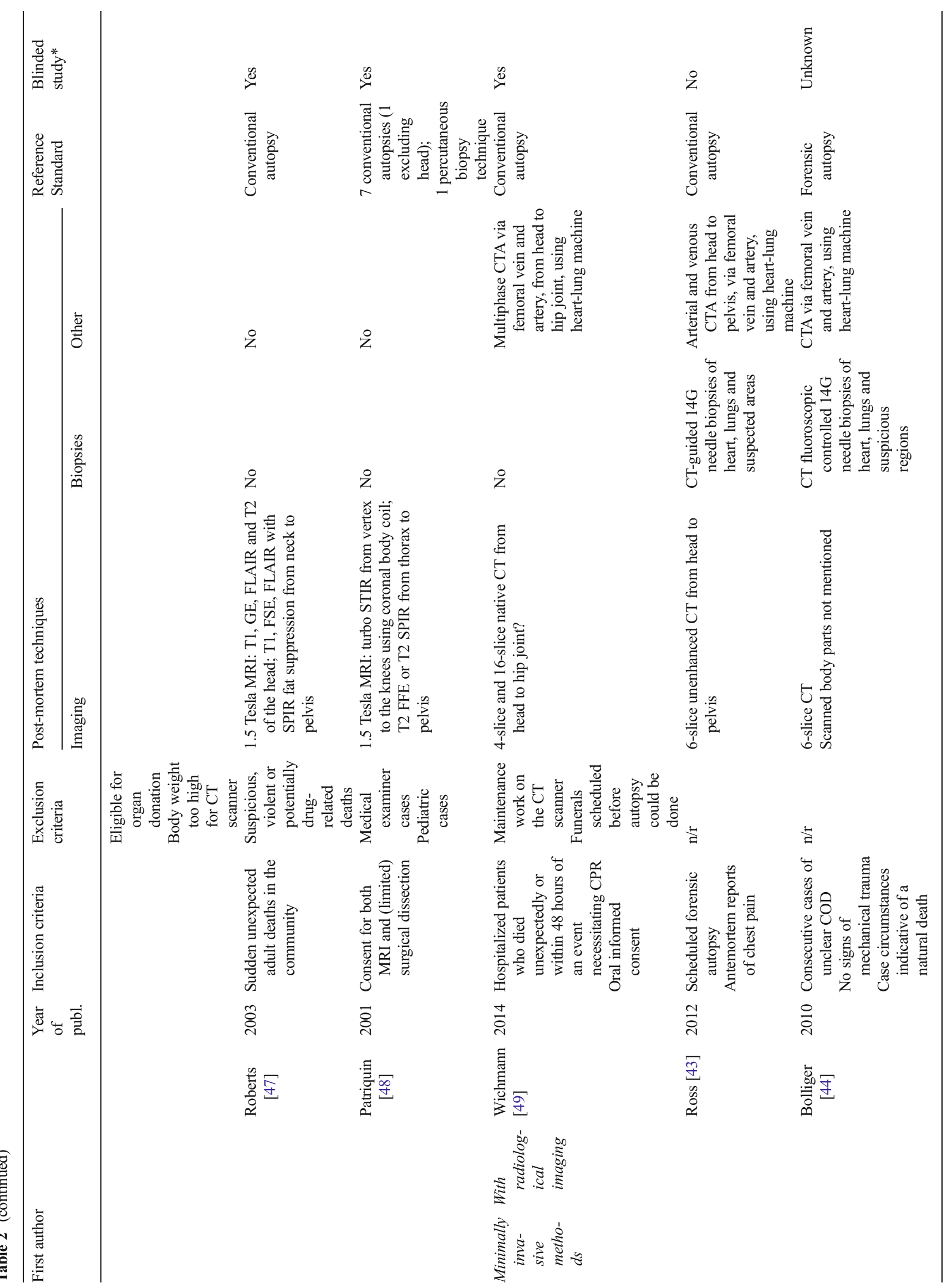




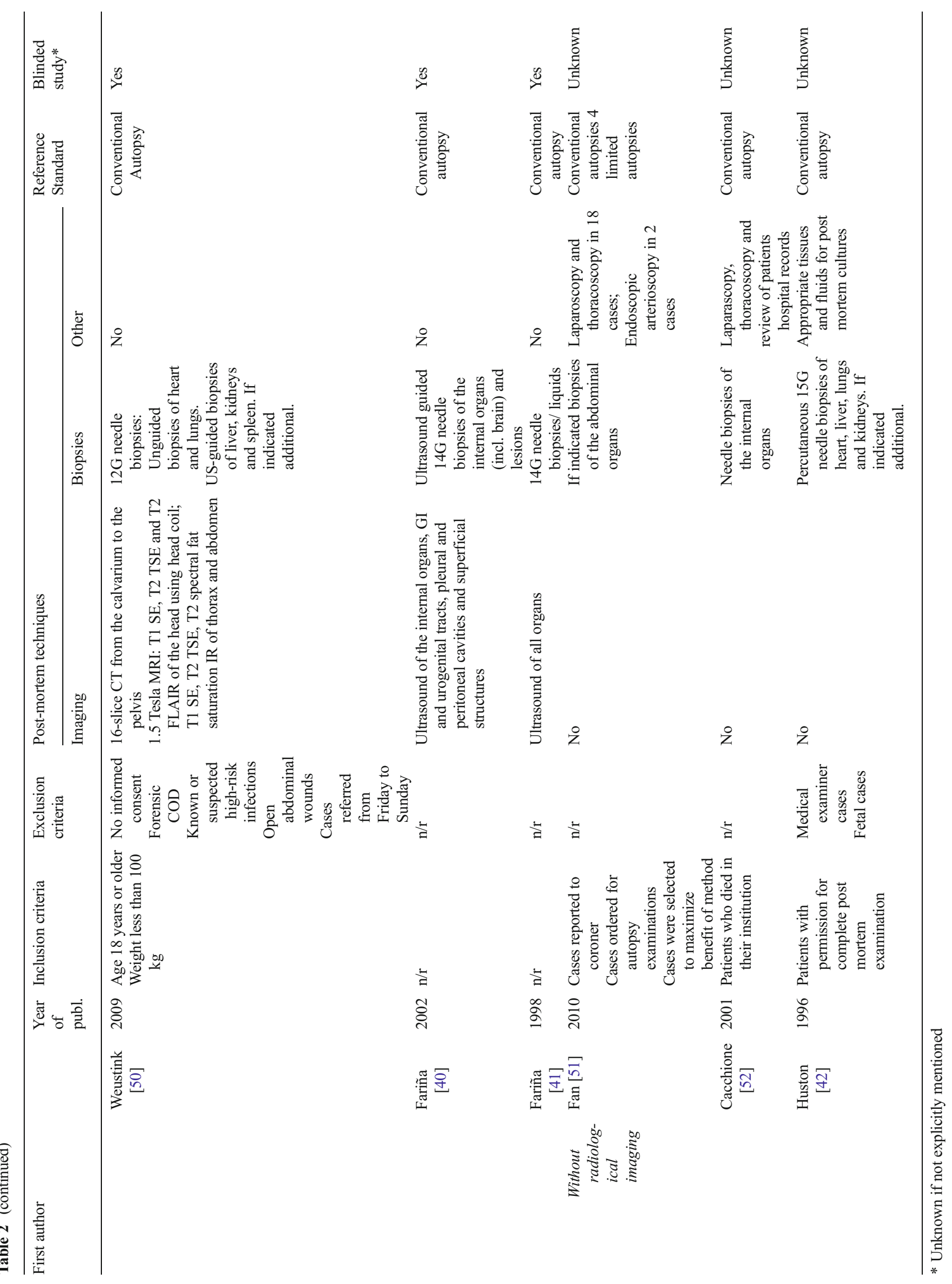




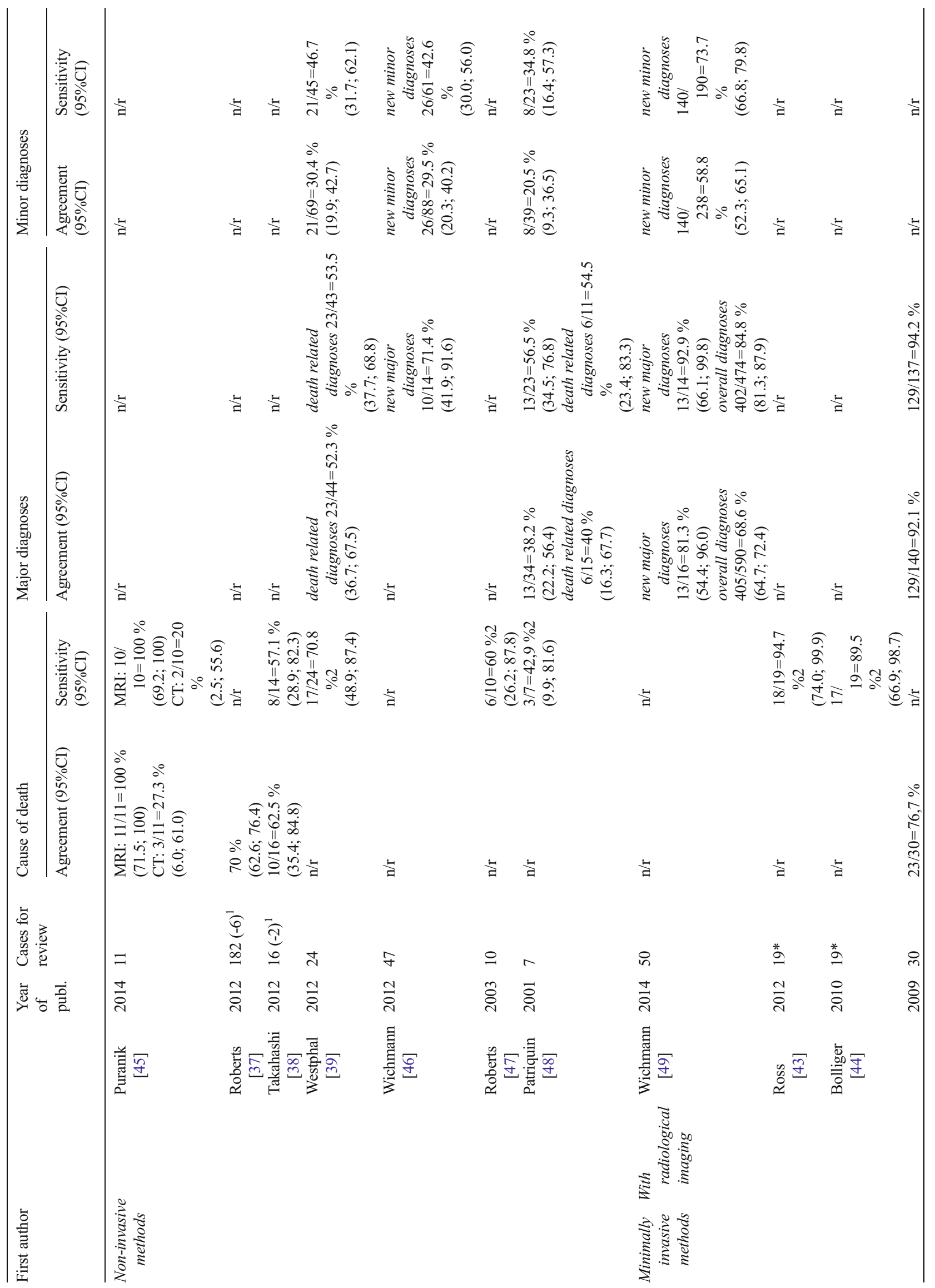




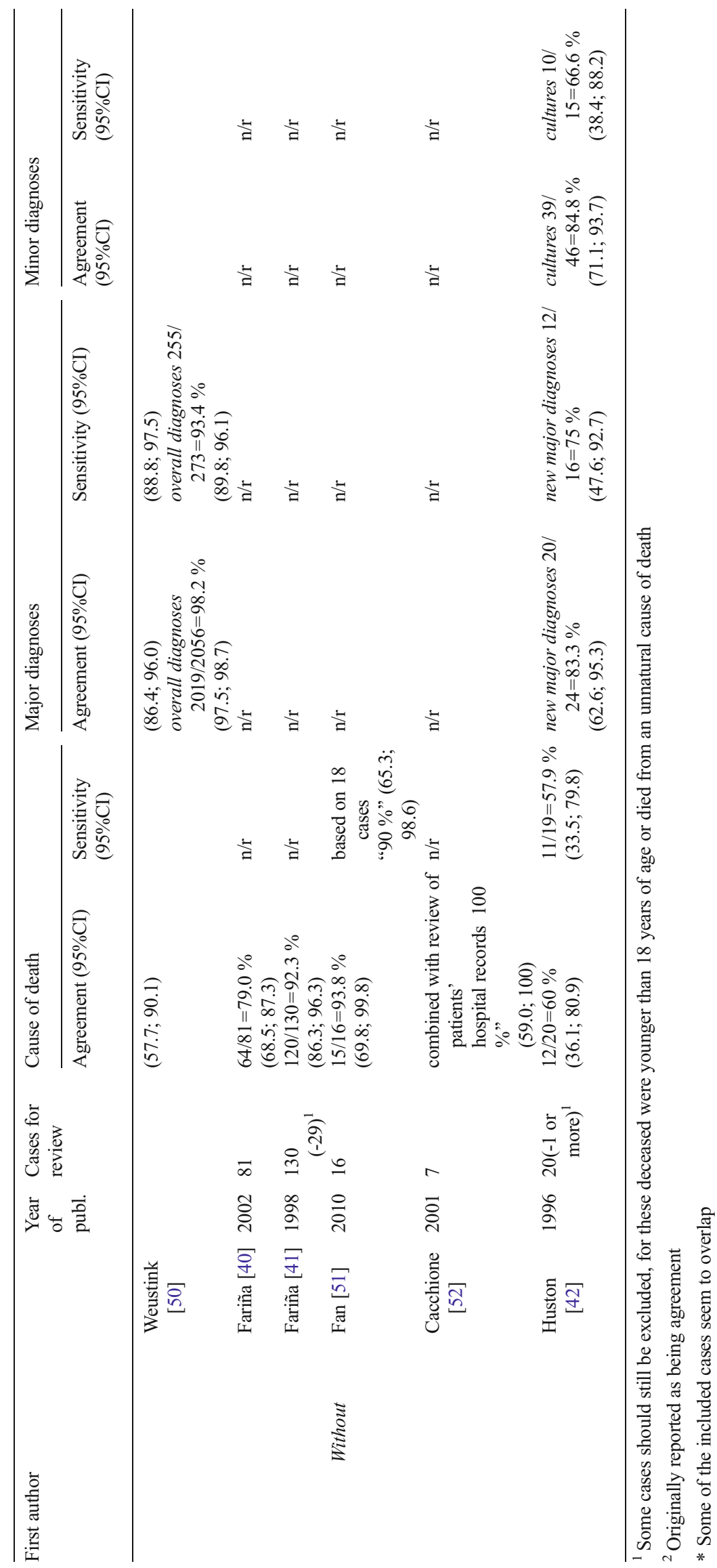


Two studies combined CT, CT-angiography and (CTguided) tissue biopsies as an alternative to conventional autopsy [43, 44], resulting in high sensitivities for cause of death: $94.7 \%$ and $89.5 \%$. Both studies included twenty cases of which six appeared to be duplicates, so together they actually included 34 cases, of which 33 were eligible for this review, leading to a pooled sensitivity of $90.9 \%(95 \%$ CI: 74.5 ; 97.6).

Further analyses or comparison between these studies was difficult, because of the heterogeneity in studied methods.

\section{Cost of alternative autopsy methods}

Although several studies mentioned costs, only one of them compared the actual cost of the two methods investigated. Weustink et al. [50] calculated a mean cost of $\$ 1497 \pm 148$ per minimally invasive autopsy, and $\$ 2274 \pm 104$ per conventional autopsy. Wichmann et al. [49] stated that the addition of angiography increased cost with $\$ 300$ per case. Roberts et al. mentioned that alternative autopsies using MRI are more expensive than conventional autopsy [37, 47]. Alternative autopsies using CT [37, 38, 46] or ultrasound [40, 41], on the other hand, appear to be less expensive than conventional autopsy.

\section{Discussion}

This is one of few systematic reviews to analyse the accuracy of alternatives to the conventional methods of autopsy in natural deaths, and the first to focus on naturally deceased adults. Although none of the alternative methods performed as well as conventional autopsy, higher agreement and sensitivity percentages demonstrated that minimally invasive autopsy methods were more accurate than non-invasive autopsy methods, especially those including tissue biopsies.

\section{Comparison with the literature}

A similar systematic review has been performed by Thayyil et al. [53], who found better overall pooled sensitivity and specificity of post-mortem MRI in foetuses (69 \% and $95 \%$ ) than in children and adults. As an alternative to conventional autopsy, however, its diagnostic accuracy was insufficient in all patient groups.

Since then, more studies have been published, and the diagnostic performance of alternative methods has improved significantly, as our study shows. With the introduction of minimally invasive autopsy methods, including imaging and tissue biopsies, remarkable improvements in accuracy were achieved. The merit of histological examination of vital organ tissue, in particular obtained under image-guidance, is also addressed in forensic studies [54].
When comparing cost, minimally invasive autopsy may be less expensive than conventional autopsy. According to the reviewed studies, a minimally invasive autopsy including both biopsies and CT-angiography costs $\$ 1649$ to $\$ 1945$, whereas an autopsy costs $\$ 2170$ to $\$ 2378$. In Switzerland each autopsy is preceded by at least CT, and Flach et al.[55] recently calculated a cost of $\$ 820$ to $\$ 1150$ per post-mortem examination including CT, CT-angiography, MRI, and forensic expert opinion.

Even though post-mortem endoscopic methods (thoracoscopy and laparoscopy) appear to be very accurate alternatives to conventional autopsy $[51,52]$, we hesitate to draw conclusions. Both studies included a fairly small number of cases and did not report whether the examiners were blinded to the conventional autopsy findings. One study states that it induced selection bias by selecting cases in order to maximize the benefit of the alternative autopsy [51]. Avrahami et al. [56] support our doubts, and state that findings from an endoscopic autopsy are insufficient to establish a definite cause of death. They recommend performing endoscopic autopsy only in cases in which there are objections to conventional autopsy and in order to rule out or identify major thoracic or abdominal pathology leading to death.

Several studies have shown that post-mortem whole-body CT-angiography visualizes pathological changes in blood vessels, such as stenosis, occlusion, and injuries, and improves the accuracy of a minimally invasive autopsy method [30, 43, $44,49,57]$. As these whole-body angiographies tend to be expensive, for heart-lung machines and large volumes of special contrast agents are required, either out-dated and therefore inexpensive equipment, or newly developed low-cost 'targeted' angiography methods are being used. For instance, a post-mortem coronary CT-angiography was designed to improve the accuracy of a minimally invasive autopsy method in sudden natural death cases [58, 59]. For findings in the coronary arteries, Roberts et al. achieved a correlation of $80 \%$ between autopsy and CT-angiography. Moreover, Saunders et al. were able to reduce the time for whole body CTscanning and a coronary CT-angiography to an average of 48 minutes.

Another interesting technique, which was not performed in any of the reviewed studies, is postmortem ventilation. In clinical practice, the detection of small lung lesions is improved by having patients hold their breath when the scan is made. To achieve a similar effect in postmortem imaging, forensic examiners simulated expiration and inspiration scans by ventilating the lungs [60-62].

When searching for validation studies of alternatives to autopsies, we also found articles about verbal autopsy. This is a WHO-method used in populations lacking vital registration and medical certification, to determine the probable cause of death based on questionnaires and/ or narratives from next of kin or other reliable informants (such as caregivers). The 
Fig. 2 a Forest plot: Agreement in cause of death. b Forest plot: Sensitivity cause of death a

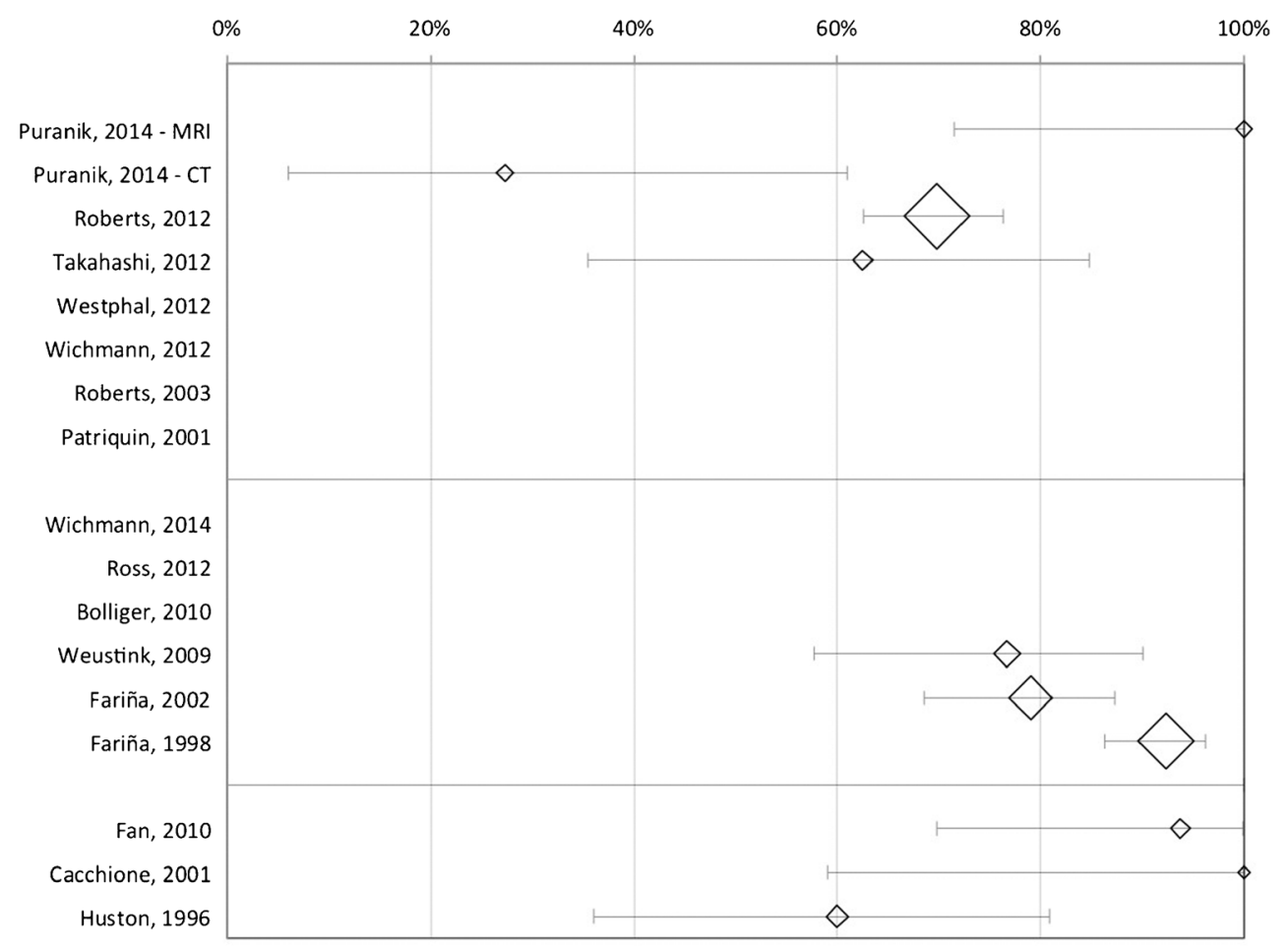

Sensitivity cause of death

b

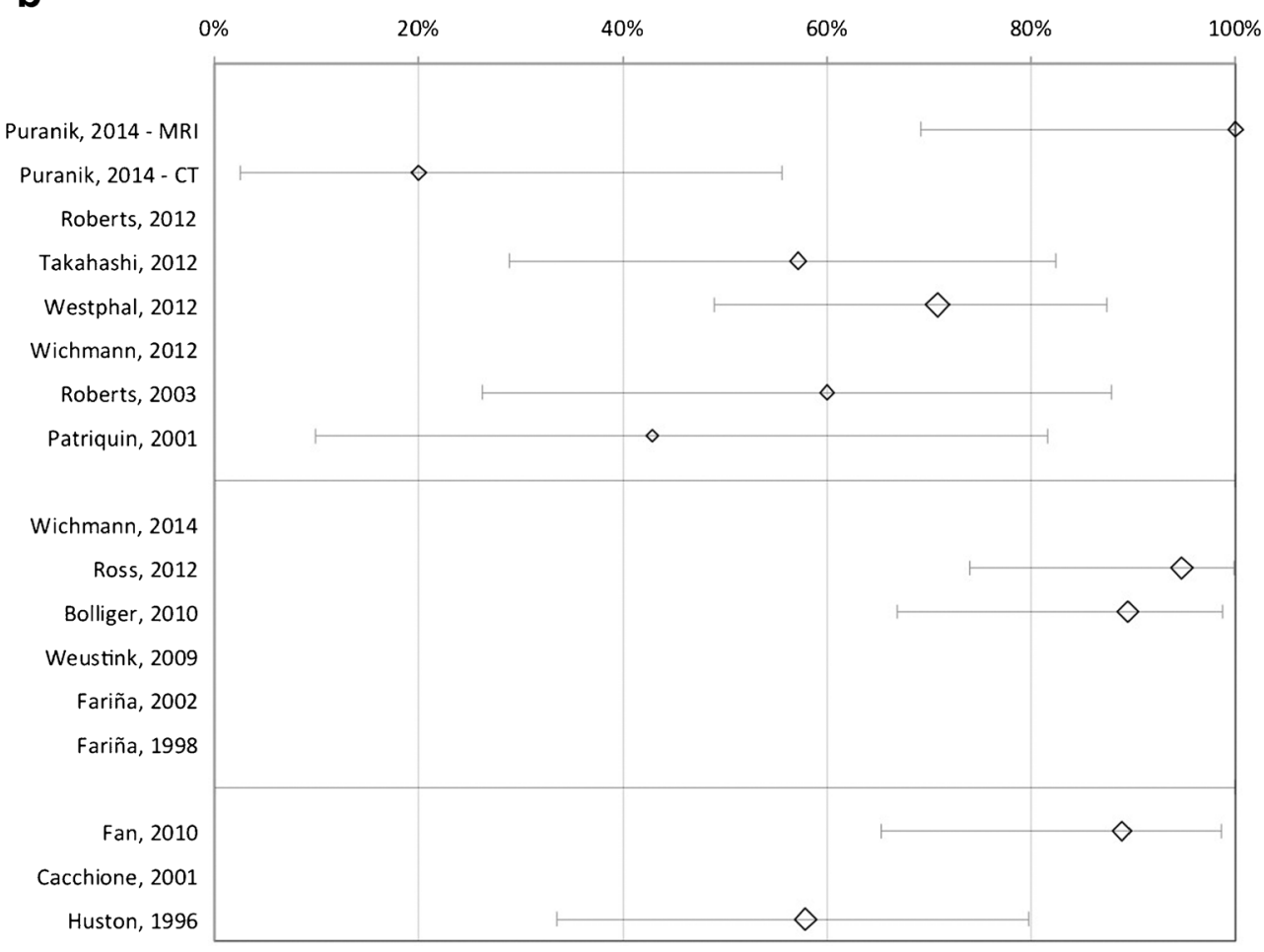

method is not based on any post-mortem physical examination of the body, and not accurate for attributing cause of death at the individual level. Therefore, verbal autopsy was excluded from this review.

\section{Limitations}

We found very few validation studies on non-invasive and minimally invasive autopsy methods performed on 
Fig. 3 Funnel plot: Validation scores for defining cause of death
Funnel plot: validation scores for defining cause of death

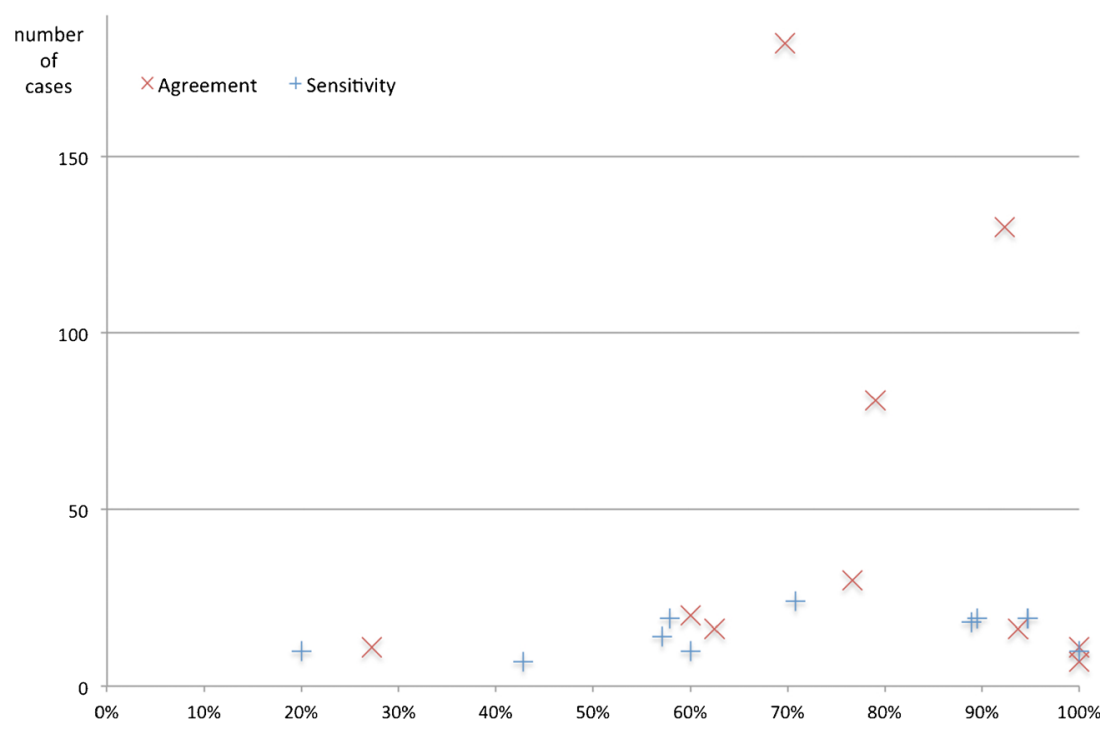

adults with a non-suspicious and supposedly natural cause of death. We therefore chose not to exclude studies that did not provide sufficient data for composing complete $2 \times 2$ tables. As a result, the agreement on cause of death could not always be calculated, as it should be based on the combined true positives and true negatives whereas the latter was frequently missing. As we could neither extract true negatives nor false positives, we calculated only sensitivity percentages, even though the results had originally been reported as being agreement percentages.

Due to insufficient data, we were also unable to test whether the agreement percentages on cause of death were any better than chance, since, with incomplete $2 \times 2$ tables, the chance-corrected proportional agreement ( $\mathrm{K}$-statistic) could not be correctly calculated.

Also, variability of the investigated study groups and study methods, and the information that was reported in the articles was too large to combine study outcomes in a meta-analysis.

For example, in studies using radiological imaging, one, two, four or six (specialized) radiologists reviewed the images. Previous experience in post-mortem imaging was mentioned in six studies: it varied from no experience to 5 years of experience, and was not comparable between studies. Roberts et al. [47] found that previous experience did not result in more correctly diagnosed causes of death. Moreover, only two studies calculated an inter-observer agreement (kappa): Weustink et al. [50] reported kappas of 0.85 for CT and 0.84 for MRI, and Ross et al. [43] reported a kappa of 0.94 .

In addition, when comparing a new method to the reference standard in a validation study, the investigators performing one method should ideally be blind to outcomes of the other. This might not have been the case in eight of the studies reviewed, in which the agreement or sensitivity percentages may have been influenced, possibly biasing their value.

Controversially, blinding induces failure to detect false positive and false negative results. Christe et al.[63] reported that both gas and fractures were better detected at imaging than autopsy. To prevent these imaging findings from being registered as false positives, they had the findings confirmed after a second look at the autopsy. The same way, taking a second look at the radiologic images after autopsy could rectify false negative results. However, in both situations the findings were not originally reported, so they may be missed again in the future.

Another limitation, which is almost inevitable due to the kind of studies investigated, is knowledge of the medical histories prior to performing autopsy. None of the reviewed studies reported that the investigators of conventional autopsy and its potential alternative were uninformed about the case circumstances. Therefore, this prior knowledge may have influenced the outcomes of agreement between the two methods, for known pathologies are more likely to be identified than unknown ones.

\section{Advantages and disadvantages of the non-invasive and minimally invasive autopsy methods}

When comparing radiological techniques for non-invasive and minimally invasive autopsy methods, CT and MRI are likely to be preferred over ultrasound. Both have their strengths and shortcomings, and may ideally complement each other. Table 4 gives an overview of the advantages and disadvantages of the radiologic techniques [32, 38, 40, 41, 49, 58, 59, 64-67]. 
Table 4 Advantages and disadvantages of non-invasive and minimally invasive autopsy methods using radiological techniques

\begin{tabular}{|c|c|c|}
\hline & Advantages & Disadvantages \\
\hline Ultrasound $[40,41]$ & $\begin{array}{l}\text { Logistics: } \\
\text { High availability } \\
\text { Operator friendly } \\
\text { Cost: } \\
\text { Inexpensive }\end{array}$ & $\begin{array}{l}\text { Image quality and diagnose: } \\
\text { Inferior to MRI and CT in image quality } \\
\text { Inferior to MRI and CT in biopsy guidance } \\
\text { Limited visualisation of the vascular system } \\
\text { (no flow) } \\
\text { Operator dependent }\end{array}$ \\
\hline CT $[38,64,65]$ & $\begin{array}{l}\text { Logistics: } \\
\text { High availability } \\
\text { Rapid whole body examination } \\
\text { Repeated scanning possible } \\
\text { Possibility of biopsy guidance } \\
\text { Cost: } \\
\text { Relatively inexpensive (compared } \\
\text { to MRI) } \\
\text { Image quality and diagnose: } \\
\text { Good visualization of bone (e.g., } \\
\text { fractures), lung parenchyma disease, } \\
\text { calcifications } \\
\text { (stones, atheroscle } \\
\text { rosis), acute haemorrhage, } \\
\text { air/ gas (e.g., pneumothorax, } \\
\text { pneumatosis intestinalis, free air) } \\
\text { High in-plane resolution (e.g. ,small } \\
\text { lung nodules) }\end{array}$ & $\begin{array}{l}\text { Logistics: } \\
\text { Limited availability during regular working } \\
\text { hours (interferes with scanning of the } \\
\text { living) } \\
\text { Image quality and diagnose: } \\
\text { Limited visualisation of pathology in soft } \\
\text { tissues and organ parenchyma } \\
\text { Limited differentiation of normal postmortem } \\
\text { changes (e.g., clotting, sedimentation) and } \\
\text { pathology (e.g., pulmonary } \\
\text { thromboembolism) } \\
\text { Limited ability to diagnose cardiac causes of death } \\
\text { (e.g., patency of coronaries, } \\
\text { acute myocardial } \\
\text { infarction) } \\
\text { Image artefacts (e.g., metal from dental } \\
\text { filling, prosthetic valves) }\end{array}$ \\
\hline
\end{tabular}

MRI $[38,65,66]$

CT Angiography $[32,49,64,65,67]$
Isovolumetric multi-planar and 3-D reconstructions

Logistics:

Possibility of biopsy guidance

Image quality and diagnose:

Good, detailed visualization of organ parenchyma

(e.g., brain, heart and myocardial infarct age), soft tissue (e.g., muscle injury), fluids (e.g,. pleural/ pericar dial), nervous system (e.g., spinal canal disorders), bone marrow disorders, metabolic diseases (e.g., hemochromatosis), large vessels (e.g., aortic dissection)

Good differentiation between postmortem changes and pathology

Image quality and diagnose:

Good detection (of the origin) of haemorrhages (e.g., aortic rupture)

Good detection of cardiovascular conditions

(e.g., coronary stenosis)

\section{Logistics:}

Limited availability during regular working hours (interferes with scanning of the living)

Relatively time consuming examination (depending on scan protocol)

Requires dedicated postmortem scan protocols (e.g., adjusting scan parameters for the body temperature)

Requires MRI compatible body bags (e.g. ,no metal)

Cost:

Relatively expensive

Requires dedicated training of technicians

Image quality and diagnose:

Image artefacts (e.g., metal from dental filling)

\section{Logistics:}

Limited availability of dedicated equipment and contrast agents

Time consuming and complicated examination

(e.g., achieving optimal contrast timing and full enhancement is difficult)

Cost:

Expensive (longer procedure time, contrast agents, dedicated equipment*) 
Table 4 (continued)

\begin{tabular}{|c|c|c|}
\hline & Advantages & Disadvantages \\
\hline \multirow{10}{*}{$\begin{array}{l}\text { Targeted CT (coronary) } \\
\text { angiography }[32,58,59]\end{array}$} & \multirow{7}{*}{$\begin{array}{l}\text { Cost: } \\
\text { Relatively inexpensive equipment } \\
\text { (compared to whole body angio } \\
\text { graphy) } \\
\text { Cannulation and scanning can be } \\
\text { performed with minimal training }\end{array}$} & Requires dedicated training \\
\hline & & Image quality and diagnose: \\
\hline & & $\begin{array}{l}\text { Differentiation between post-mortem clotting } \\
\text { and embolus is difficult }\end{array}$ \\
\hline & & $\begin{array}{l}\text { Lack of circulation and insufficient mixing } \\
\text { of blood and contrast }\end{array}$ \\
\hline & & Logistics: \\
\hline & & \multirow[t]{2}{*}{$\begin{array}{l}\text { Time consuming examination (e.g., positioning } \\
\text { catheter, turning the corpse) }\end{array}$} \\
\hline & & \\
\hline & Image quality and diagnose: & Image quality and diagnose: \\
\hline & \multirow{2}{*}{$\begin{array}{l}\text { Less expensive than whole body } \\
\text { angiography }\end{array}$} & Images restricted to coronary arteries \\
\hline & & $\begin{array}{l}\text { Limited visualisation of internal mammary grafts, } \\
\text { due to balloon position in the ascending aorta }\end{array}$ \\
\hline
\end{tabular}

* Less expensive if out-dated equipment were used

Both radiologic techniques and scopic techniques are generally used in medical practice for the living. Hence, they are not available for autopsy cases during busy working hours. If a technique were to be purchased for post-mortem investigations only, the costs may not outweigh the benefits. The more advanced an alternative autopsy technique is, the higher is its price, but, in general, the better are its diagnostic capabilities (if the reviewed studies had used all available techniques, their results would inevitably have been better). Yet, those capabilities are not always required for each individual autopsy case. For example, MRI should preferably be used to examine congenital abnormalities or neurologic pathology in neonates, infants and children, whereas $\mathrm{CT}$ is required to examine lung pathology in adults.

Without reliable criteria for selecting those techniques or protocols required based on individual case characteristics, it is impossible to minimize cost and enable investigators to identify or rule out specific pathologies. In order to determine an adequate strategy, that is not unduly expensive, more studies should be performed on large study groups that represent patients with all causes of death.

According to the articles reviewed difficulties remain, even with the advanced minimally invasive autopsy techniques. The main difficulties are in detecting small metastases [49]; in diagnosing cardiovascular disease, such as (localized or massive) acute myocardial infarction and endocarditis [43, 44, 46, 50]; and in distinguishing post-mortem clotting from true thromboembolic material, especially in the pulmonary arteries [43, 46]. On the other hand, in certain cases post-mortem imaging has a diagnostic advantage, since some death-related findings are better depicted on imaging than with conventional autopsy. For example, a pneumothorax was diagnosed on imaging only and missed at autopsy $[50,68]$.
To achieve the highest diagnostic accuracy we think an alternative autopsy method should at least be minimally invasive. Even though the minimally invasive autopsy method is not yet as accurate as conventional autopsy, some of its other features favour this alternative method.

The first is that imaging data can easily be stored and subjected to a second reading, and used for clinical feedback and teaching purposes, whereas macroscopic autopsy findings have to be photographed or organs have to be preserved in order to do so.

Another benefit of a minimally invasive autopsy is the possibility to take tissue biopsies under precise CT-guidance from very small lesions. It is known that in patients who died from metastatic disease, scarcely enlarged lymph nodes could be detected at conventional autopsy.

Just as in conventional autopsy, one could collect extra tissue biopsies that can be frozen and stored in a tissue bank. Such frozen samples could be used for further diagnostic analyses on a molecular level, and be used for medical research [69].

A logistic advantage of minimally invasive autopsy is that a specialised radiologist is able to read the images from another location and even plan the exact coordinates of the biopsy trajectories for a robot to precisely place the introducer needles $[31,70]$. If multiple biopsies are routinely obtained, certain advanced techniques will minimize procedure time and eventually help reducing cost. From a technological point of view, Lundström et al. [71] see no obstacles to introducing minimally invasive autopsies on a larger scale.

Fryer et al. [68] emphasize the benefit of using a minimally invasive method for screening prior to conventional autopsy in cases with high-risk infections. Among a group of suddenly deceased drug users with a known category 3 infection (such as Human Immunodeficiency Virus or hepatitis-C virus), they identified the cause of death through a minimally invasive 
examination in a considerable percentage of cases, thereby achieving a two-thirds reduction in the number of high-risk invasive autopsies.

Last but not least, clinicians would gain more information from an alternative autopsy than from no post-mortem investigation at all.

\section{Conclusion}

Non-invasive or minimally invasive autopsy methods could serve as an alternative to conventional autopsy. However, it should be remembered that these alternative methods are still less accurate than the reference standard, and that taking image-guided tissue biopsies for histological examination (and therefore performing a minimally invasive autopsy) is essential for achieving the best possible diagnostic accuracy.

To improve the technical aspects of minimally invasive autopsy methods and to test their potential in larger study groups, including patients who died in hospital with a broad spectrum of diseases, there is a need for more extensive studies. Such studies should not just examine the practical use and accuracy of the alternative autopsy method, but also take into account the cost of implementing the alternative method. If possible, an alternative to conventional autopsy should be developed that is suitable for implementation in academic and nonacademic hospitals. Such alternatives to conventional autopsy should ultimately contribute to increasing autopsy rates, improving medical feedback to clinicians, and better overall health care quality control.

\begin{abstract}
Acknowledgments We would like to thank Wichor Bramer, biomedical information specialist in our medical library, who helped perform the literature searches and Nikola Vitlarov, MD, who assisted with the data extraction. The scientific guarantor of this publication is Britt M. Blokker. None of the authors has a conflict of interest, some do have financial relationships outside the submitted work. This study has received funding by an internal grant of the Erasmus MC Health Care Efficiency Research in 2011 (Minimally Invasive Autopsy: An Alternative to Conventional Autopsy?). One of the authors has significant statistical expertise. Institutional Review Board approval or ethical approval was not required because it was a systematic review. Written informed consent was not required for this study because it was a systematic review. All of the study subjects or cohorts have been previously reported, since the articles that we reviewed were already published.
\end{abstract}

\section{Appendix 1: Search terms for systematic review on non- or minimally invasive alternatives to autopsy}

\section{Embase}

(((autopsy/de OR 'posthumous care'/de OR (autops* OR preautops* OR necrops* OR necroscop* OR obducti* OR postmort* OR (post NEAR/1 mort*) OR posthumous):ab,ti) AND ('imaging and display'/exp OR 'minimally invasive procedure'/de OR 'computer assisted tomography'/exp OR 'nuclear magnetic resonance'/exp OR endoscopy/exp OR (((mini OR minimal* OR non) NEAR/1 (invas*)) OR tomograph* OR CT OR CAT OR MSCT OR PMCT OR 'magnetic resonance' OR MR OR MRI OR endoscop* OR scop* OR laparoscop* OR thoracoscop* OR virtual OR imaging OR radiolog* OR alternative*):ab,ti) AND ('cause of death'/de OR ((cause*) NEAR/3 (death)) OR deathcause*):ab,ti)) OR (((alternativ* OR endoscop* OR scop* OR laparoscop* OR thoracoscop* OR virtual OR imaging) NEAR/3 (preautops* OR autops*)) OR virtops*):ab,ti) NOT 'case report'/de NOT ([animals]/lim NOT [humans]/lim) NOT ((child/exp OR newborn/exp OR fetus/exp OR 'fetus death'/de OR 'perinatal death'/de) NOT (adult/exp OR aged/ exp OR 'middle aged'/exp)) AND ('comparative study'/exp OR 'validation study'/de OR 'feasibility study'/de OR 'quality control procedures'/exp OR reliability/exp OR 'diagnostic accuracy'/de OR evaluation/de OR 'sensitivity analysis'/de OR (compar* OR validat* OR feasib* OR qualit* OR sensitiv* OR specific* OR reliab* OR accura* OR evaluat* OR intermethod* OR Reproducib*):ab,ti)

\section{Medline OvidSP}

(((autopsy/ OR (autops* OR preautops* OR necrops* OR necroscop* OR obducti* OR postmort* OR (post ADJ mort*) OR posthumous).ab,ti.) AND (exp "Diagnostic Imaging"/ OR exp "Surgical Procedures, Minimally Invasive"/ OR (((mini OR minimal* OR non) ADJ (invas*)) OR tomograph* OR CT OR CAT OR MSCT OR PMCT OR "magnetic resonance" OR MR OR MRI OR endoscop* OR scop* OR laparoscop* OR thoracoscop* OR virtual OR imaging OR radiolog* OR alternative*).ab,ti.) AND ("cause of death"/ OR (((cause*) ADJ3 (death)) OR deathcause*).ab,ti.)) OR (((alternativ* OR endoscop* OR scop* OR laparoscop* OR thoracoscop* OR virtual OR imaging) ADJ3 (preautops* OR autops*)) OR virtops*).ab,ti.) NOT "case report".pt. NOT (exp animals/ NOT humans/) NOT ((exp child/ OR exp infant/ OR exp fetus/ OR exp "fetal death"/) NOT (exp adult/)) AND ("comparative study".pt. OR "validation study".pt. OR "feasibility studies"/ OR "Sensitivity and Specificity"/ OR "Reproducibility of Results"/ OR "Evaluation Studies".pt. OR (compar* OR validat* OR feasib* OR qualit* OR sensitiv* OR specific* OR reliab* OR accura* OR evaluat* OR intermethod* OR Reproducib*).ab,ti.)

\section{Cochrane}

((((autops* OR preautops* OR necrops* OR necroscop* OR obducti* OR postmort* OR (post NEAR/1 mort*) OR posthumous):ab,ti) AND ((((mini OR minimal* OR 
non) NEAR/1 (invas*)) OR tomograph* OR CT OR CAT OR MSCT OR PMCT OR 'magnetic resonance' OR MR OR MRI OR endoscop* OR scop* OR laparoscop* OR thoracoscop* OR virtual OR imaging OR radiolog* OR alternative*):ab,ti) AND ((((cause*) NEAR/3 (death)) OR deathcause*):ab,ti)) OR (((alternativ* OR endoscop* OR scop* OR laparoscop* OR thoracoscop* OR virtual OR imaging) NEAR/3 (preautops* OR autops*)) OR virtops*):ab,ti) AND ((compar* OR validat* OR feasib* OR qualit* OR sensitiv* OR specific* OR reliab* OR accura* OR evaluat* OR intermethod* OR Reproducib*):ab,ti)

\section{Web-of-Science}

TS $=((((($ autops $*$ OR preautops $*$ OR necrops* OR necroscop* OR obducti* OR postmort* OR (post NEAR/1 mort*) OR posthumous)) AND ((((mini OR minimal* OR non) NEAR/1 (invas*)) OR tomograph* OR CT OR CAT OR MSCT OR PMCT OR "magnetic resonance" OR MR OR MRI OR endoscop* OR scop* OR laparoscop* OR thoracoscop* OR virtual OR imaging OR radiolog* OR alternative*)) AND ((((cause*) NEAR/3 (death)) OR deathcause*))) OR (((alternativ* OR endoscop* OR scop* OR laparoscop* OR thoracoscop* OR virtual OR imaging) NEAR/3 (preautops* OR autops*)) OR virtops*)) AND ((compar* OR validat* OR feasib* OR qualit* OR sensitiv* OR specific* OR reliab* OR accura* OR evaluat* OR intermethod* OR Reproducib*)) NOT ((animal* OR swine OR rat OR rats OR dog OR dogs OR cat OR cats OR monkey* OR donkey* OR horse*) NOT (human* OR patient*)))

The literature search in these databases was performed together with a biomedical information specialist. The search terms included the following elements: autopsy, imaging, cause of death and validation. These were translated into thesaurus terms (mesh or emtree) and free text words in title and/ or abstract. Case reports, studies on children and animal studies were filtered out.

Initially, we reviewed 1121 articles (see Table S1 in appendix 2).

Using EndNote specific software commands, we identified which search results were duplicates of articles reviewed in the initial literature search, 351 of the 1468 articles in Table S2 remained to be reviewed in the second literature search.

Using EndNote specific software commands, we identified which search results were duplicates of articles reviewed in the previous literature searches, 69 of the 1506 articles in Table S3 remained to be reviewed in the third literature search.
Appendix 2: Overview of the number of results in literature searches per database

Table S1

Table S1 Initial literature search results on the 16th of July, 2013

\begin{tabular}{lll}
\hline & Total & After deduplication \\
\hline Embase & 624 & 614 \\
Medline OvidSP & 604 & 214 \\
Web-of-Science & 646 & 293 \\
Cochrane & 5 & 0 \\
Total & $\mathbf{1 8 7 9}$ & $\mathbf{1 1 2 1}$ \\
\hline
\end{tabular}

Table S2

Table S2 New results from repeated literature search on the 1st of April, 2014

\begin{tabular}{lll}
\hline & Total & After deduplication \\
\hline Embase & 691 & 687 \\
Medline OvidSP & 630 & 242 \\
Web-of-Science & 707 & 325 \\
PubMed publisher & 55 & 54 \\
Cochrane & 6 & 1 \\
Google Scholar & 200 & 159 \\
Total & $\mathbf{2 2 8 9}$ & $\mathbf{1 4 6 8}$ \\
\hline
\end{tabular}

Table S3

Table S3 New results from repeated literature search on the 27th of June, 2014

\begin{tabular}{lll}
\hline & Total & After deduplication \\
\hline Embase & 713 & 709 \\
Medline OvidSP & 649 & 249 \\
Web-of-Science & 732 & 338 \\
PubMed publisher & 56 & 53 \\
Cochrane & 6 & 1 \\
Google Scholar & 200 & 156 \\
Total & $\mathbf{2 3 5 6}$ & $\mathbf{1 5 0 6}$ \\
\hline
\end{tabular}

\section{Appendix 3: List of potentially relevant articles in literature searches}

1. Westphal SE, Apitzsch J, Penzkofer T, Mahnken AH, Knuchel R. Virtual CT autopsy in clinical pathology: Feasibility in clinical autopsies. Virchows Arch 2012; 461:211-219. 
2. Weustink AC, Hunink MGM, Van Dijke CF, Renken NS, Krestin GP, Oosterhuis JW. Minimally invasive autopsy: An alternative to conventional autopsy? Radiology 2009; 250:897-904.

3. Fan JKM, Tong DKH, Poon JTC, et al. Multimodality minimally invasive autopsy-A feasible and accurate approach to post-mortem examination. Forensic Sci Int 2010; 195:9398.

4. Roberts ISD, Benamore RE, Benbow EW, et al. Postmortem imaging as an alternative to autopsy in the diagnosis of adult deaths: A validation study. Lancet 2012; 379:136-142.

5. Roberts ISD, Benamore R, Benbow EW, et al. Postmortem imaging as an alternative to autopsy: Development of techniques for improving diagnostic accuracy. Lab Invest 2010; 90:13A.

6. Ross SG, Thali MJ, Bolliger S, Germerott T, Ruder TD, Flach PM. Sudden death after chest pain: Feasibility of virtual autopsy with postmortem CT angiography and biopsy. Radiology 2012; 264:250-259.

7. Iyengar S, Gosling O, Morgan-Hughes G, Roberts I, Roobottom C. Diagnostic accuracy of post-mortem cardiac imaging (PMI) in the assessment of cardiac cause of sudden death: Radiology-pathology correlation. J Cardiovasc Comput Tomogr 2011; 5:S74.

8. Flach PM, Flach PM, Ross S, et al. Virtopsy: Feasibility of postmortem CT angiography in neuropathological cases. Schweiz Arch Neurol Psychiatr 2010; 161:48S.

9. Bolliger SA, Filograna L, Spendlove D, Thali MJ, Dirnhofer S, Ross S. Postmortem imaging-guided biopsy as an adjuvant to minimally invasive autopsy with $\mathrm{CT}$ and postmortem angiography: A feasibility study. Am J Roentgenol 2010; 195:1051-1056.

10. Avrahami R, Watemberg S, Hiss Y. Thoracoscopy vs conventional autopsy of the thorax: A promising perspective. ARCH SURG 1995; 130:956-958.

11. Avrahami R, Watemberg S, Hiss Y, Deutsch AA, Hutchins GM. Laparoscopic vs conventional autopsy: A promising perspective. ARCH SURG 1995; 130:407409.

12. Cha JG, Kim DH, Kim DH, et al. Utility of postmortem autopsy via whole-body imaging: Initial observations comparing MDCT and 3.0 T MRI findings with autopsy findings. Kor J Radiol 2010; 11:395-406.

13. Cacchione RN, Sayad P, Pecoraro AM, Ferzli GS. Laparoscopic autopsies. Surg Endosc 2001; 15:619-622.

14. Roberts ISD, Benbow EW, Bisset R, et al. Accuracy of magnetic resonance imaging in determining cause of sudden death in adults: Comparison with conventional autopsy. Histopathology 2003; 42:424-430.

15. Patriquin L, Kassarjian A, O'Brien M, Andry C, Eustace S. Postmortem whole-body magnetic resonance imaging as an adjunct to autopsy: Preliminary clinical experience. J Magn Reson Imaging 2001; 13:277-287.
16. Shiotani S, Kohno M, Ohashi N, et al. Non-traumatic postmortem computed tomographic (PMCT) findings of the lung. Forensic Sci Int 2004; 139:39-48.

17. Yamazaki K, Shiotani S, Ohashi N, Doi M, Honda K. Hepatic portal venous gas and hyper-dense aortic wall as postmortem computed tomography finding. Legal Med 2003; 5:S338-S341.

18. Paperno S, Riepert T, Krug B, et al. Value of postmortem computed tomography in comparison to autopsy. RoFo Fortschr Geb Rontgenstr Bildgebenden Verfahren 2005; 177:130-136.

19. Vogel B, Gulbins H, Reichenspurner H, Heinemann A, Vogel $\mathrm{H}$. The operated heart in post-mortem computed tomography. Interact Cardiovasc Thorac Surg 2012; 15:S106.

20. Jackowski C, Warntjes MJB, Berge J, Bar W, Persson A. Magnetic resonance imaging goes postmortem: Noninvasive detection and assessment of myocardial infarction by postmortem MRI. Eur Radiol 2011; 21:70-78.

21. Wichmann D, Obbelode F, Vogel H, et al. Virtual autopsy as an alternative to traditional medical autopsy in the intensive care unit; A prospective cohort study. Ann Intern Med 2012; 156:123-130.

22. Sugawara S, Mizunuma K, Kato K, Toshiyasu T. Evaluation of postmortem CT (PMCT) to diagnose the cause of death. Jpn J Clin Radiol 2006; 51:845-850.

23. Takahashi N, Higuchi T, Shiotani M, et al. The effectiveness of postmortem multidetector computed tomography in the detection of fatal findings related to cause of nontraumatic death in the emergency department. Eur Radiol 2012; 22:152-160.

24. Wichmann D, Obbelode F, Vogel H, Hopker WW, Puschel K, Kluge S. Virtual autopsy: A new approach for quality control in the intensive care unit. Intensive Care Med 2011; 37:S35.

25. Farina J, Millana C, Fdez-Acenero JM, et al. Ultrasonographic autopsy (echopsy): A new autopsy technique. Virchows Arch 2002; 440:635-639.

26. Farina J, Millana C. Applications of ultrasonography on the post-mortem examination (ecopsy) in humans. J Echogr Med Ultrasons 1998; 19:280-286.

27. Rutty GN, Swift B. Accuracy of magnetic resonance imaging in determining cause of sudden death in adults: Comparison with conventional autopsy [1]. Histopathology 2004; 44:187-189.

28. Ruder TD, Bauer-Kreutz R, Ampanozi G, et al. Assessment of coronary artery disease by post-mortem cardiac MR. Eur J Radiol 2012; 81:2208-2214.

29. Vernooij MW. Minimally invasive autopsy: the technological revival of autopsy? Eur J Epidemiol 2012; 27:487-488.

30. Friedrich MJ. Can imaging help revive the autopsy? J Am Med Assoc 2012; 307:1471-1472.

31. Huston BM, Malouf NN, Azar HA. Percutaneous needle autopsy sampling. MOD PATHOL 1996; 9:1101-1107. 
32. Farina Gonzalez J. Ultrasonographic autopsy: a minimally invasive postmortem technique. An R Acad Nac Med (Madr) 1998; 115:703-716; discussion 716-717.

33. Watts G. Pathology: Imaging the dead. BMJ (Online) 2010; 341:1130-1131.

34. Burton EC, Mossa-Basha M. To image or to autopsy? Ann Intern Med 2012; 156:158-159.

35. Farina J, Millana MC, Fernandez-Acenero MJ. Ultrasonographic autopsy [1]. Histopathology 2004; 45:298.

36. Ros PR, Li KC, Vo P, Baer H, Staab EV. Preautopsy magnetic resonance imaging: initial experience. Magn Reson Imaging 1990; 8:303-308.

37. Schenk M. [Virtual versus traditional autopsy] German. DTSCH MED WOCHENSCHR 2012; 137:p11.

38. Roberts ISD, Benamore R, Benbow EW, et al. PostMortem Imaging as an Alternative to Autopsy: Development of Techniques for Improving Diagnostic Accuracy. Modern Pathology 2010; 23:13A-13A.

39. Roberts ISD, Benbow EW, Bissett R, et al. Accuracy of Magnetic Resonance Imaging (MRI) in determining cause of death: A potential alternative to the autopsy? Journal of Pathology 2000; 192:9A-9A.

40. Roberts ISD. Imaging and the autopsy. J Pathol 2013; 231:S9.

41. Roberts ISD, Traill ZC. Minimally invasive autopsy employing post-mortem $\mathrm{CT}$ and targeted coronary angiography: Evaluation of its application to a routine Coronial service. Histopathology 2014; 64:211-217.

42. Vogel B, Gulbins H, Reichenspurner H, Heinemann A, Vogel H. Findings in post mortem computed tomography (PMCT) after cardiac surgery of the adult. Thorac Cardiovasc Surg 2013; 61.

43. Bassat Q, Ordi J, Vila J, et al. Development of a post-mortem procedure to reduce the uncertainty regarding causes of death in developing countries. Lancet Global Health 2013; 1:E125-E126.

44. Bisset R. Magnetic resonance imaging may be alternative to necropsy. BMJ: British Medical Journal 1998.

45. Hayakawa M, Yamamoto S, Motani H, Yajima D. Does imaging technology overcome problems of conventional postmortem examination? International journal of ... 2006.

46. Roberts ISD, Benamore, R. E., Peebles, C., Roobottomd, C., Traill, Z. C. Diagnosis of coronary artery disease using minimally invasive autopsy: evaluation of a novel method of post-mortem coronary CT angiography. Clinical Radiology 2011; 66:645-650.

47. Donnell CO, Woodford N. Post-mortem radiology-a new sub-speciality? Clinical Radiology 2008.

48. Ezawa H, Yoneyama R, Kandatsu S. Introduction of autopsy imaging redefines the concept of autopsy: 37 cases of clinical experience. Pathology ... 2003.
49. Michaud K, Grabherr S, Doenz F, Mangin P. Evaluation of postmortem MDCT and MDCT-angiography for the investigation of sudden cardiac death related to atherosclerotic coronary artery disease. Int J Cardiovasc Imaging 2012; 28:1807-1822.

50. Puranik R GB, Lackey H, Yeates L, Parker G, Duflou J, Semsarian C. Comparison of conventional autopsy and magnetic resonance imaging in determining the cause of sudden death in the young. J Cardiovasc Magn Reson. 2014; 16:44.

51. Wichmann D, Heinemann A, Weinberg C, et al. Virtual Autopsy With Multiphase Postmortem Computed Tomographic Angiography Versus Traditional Medical Autopsy to Investigate Unexpected Deaths of Hospitalized Patients. Annals of Internal Medicine 2014; 160:534-+.

Open Access This article is distributed under the terms of the Creative Commons Attribution-NonCommercial 4.0 International License (http:// creativecommons.org/licenses/by-nc/4.0/), which permits any noncommercial use, distribution, and reproduction in any medium, provided you give appropriate credit to the original author(s) and the source, provide a link to the Creative Commons license, and indicate if changes were made.

\section{Reference}

1. Burton EC (2002) The autopsy: a professional responsibility in assuring quality of care. Am J Med Qual 17:56-60

2. Lundberg GD (1998) Low-tech autopsies in the era of high-tech medicine: continued value for quality assurance and patient safety. JAMA 280:1273-1274

3. Shojania KG, Burton EC, McDonald KM, Goldman L (2002) The autopsy as an outcome and performance measure. Evid Rep Technol Assess (Summ):1-5.

4. Burton EC, Troxclair DA, Newman WP 3rd (1998) Autopsy diagnoses of malignant neoplasms: how often are clinical diagnoses incorrect? JAMA 280:1245-1248

5. Murken DR, Ding M, Branstetter BF, Nichols L (2012) Autopsy as a quality control measure for radiology, and vice versa. AJR Am J Roentgenol 199:394-401

6. Roulson J, Benbow EW, Hasleton PS (2005) Discrepancies between clinical and autopsy diagnosis and the value of post mortem histology; a meta-analysis and review. Histopathology 47:551-559

7. Scordi-Bello IA, Kalb TH, Lento PA (2010) Clinical setting and extent of premortem evaluation do not predict autopsy discrepancy rates. Mod Pathol 23:1225-1230

8. Shojania KG, Burton EC, McDonald KM, Goldman L (2003) Changes in rates of autopsy-detected diagnostic errors over time: a systematic review. JAMA 289:2849-2856

9. Veress B, Alafuzoff I (1994) A retrospective analysis of clinical diagnoses and autopsy findings in 3,042 cases during two different time periods. Hum Pathol 25:140-145

10. Winters B, Custer J, Galvagno SM et al (2012) Diagnostic errors in the intensive care unit: a systematic review of autopsy studies. Bmj Qual Saf 21:894-902

11. Wittschieber D, Klauschen F, Kimmritz AC et al (2012) Who is at risk for diagnostic discrepancies? Comparison of pre- and postmortal diagnoses in 1800 patients of 3 medical decades in 
East and West Berlin. PLoS One 7, e37460. doi:10.1371/journal. pone. 0037460

12. Burton JL, Underwood J (2007) Clinical, educational, and epidemiological value of autopsy. Lancet 369:1471-1480

13. Gaensbacher S, Waldhoer T, Berzlanovich A (2012) The slow death of autopsies: A retrospective analysis of the autopsy prevalence rate in Austria from 1990 to 2009. Eur J Epidemiol 27:577-580

14. Shojania KG, Burton EC (2008) The vanishing nonforensic autopsy. N Engl J Med 358:873-875

15. Brown HG (1990) Perceptions of the autopsy: views from the lay public and program proposals. Hum Pathol 21:154-158

16. Burton JL, Underwood JC (2003) Necropsy practice after the "organ retention scandal": requests, performance, and tissue retention. J Clin Pathol 56:537-541

17. Burton EC, Phillips RS, Covinsky KE et al (2004) The relation of autopsy rate to physicians' beliefs and recommendations regarding autopsy. Am J Med 117:255-261

18. Charlton R (1994) Autopsy and medical education: a review. J R Soc Med 87:232-236

19. Gatrad AR (1994) Muslim customs surrounding death, bereavement, postmortem examinations, and organ transplants. BMJ 309: $521-523$

20. Hinchliffe SA, Godfrey HW, Hind CR (1994) Attitudes of junior medical staff to requesting permission for autopsy. Postgrad Med J 70:292-294

21. Hull MJ, Nazarian RM, Wheeler AE, Black-Schaffer WS, Mark EJ (2007) Resident physician opinions on autopsy importance and procurement. Hum Pathol 38:342-350

22. Loughrey MB, McCluggage WG, Toner PG (2000) The declining autopsy rate and clinicians' attitudes. Ulster Med J 69:83-89

23. Oluwasola OA, Fawole OI, Otegbayo AJ, Ogun GO, Adebamowo CA, Bamigboye AE (2009) The autopsy: knowledge, attitude, and perceptions of doctors and relatives of the deceased. Arch Pathol Lab Med 133:78-82

24. Tsitsikas DA, Brothwell M, Chin Aleong JA, Lister AT (2011) The attitudes of relatives to autopsy: a misconception. J Clin Pathol 64: $412-414$

25. Sanchez H, Collins, K.A. (2013) Autopsy Request Process. http:// emedicine.medscape.com/article/1730552-overview - accessed November 19th, 2013

26. Ayoub T, Chow J (2008) The conventional autopsy in modern medicine. J R Soc Med 101:177-181

27. Brookes JAS, HallCraggs MA, Sams VR, Lees WR (1996) Noninvasive perinatal necropsy by magnetic resonance imaging. Lancet 348:1139-1141

28. Griffiths PD, Paley MNJ, Whitby EH (2005) Post-mortern MRI as an adjunct to fetal or neonatal autopsy. Lancet 365:1271-1273

29. Leth PM (2007) The Use of CT Scanning in Forensic Autopsy. Forensic Sci Med Pathol 3:65-69

30. Dirnhofer R, Jackowski C, Vock P, Potter K, Thali MJ (2006) VIRTOPSY: minimally invasive, imaging-guided virtual autopsy. Radiographics 26:1305-1333

31. Ebert LC, Ptacek W, Naether S et al (2010) Virtobot-a multifunctional robotic system for 3D surface scanning and automatic post mortem biopsy. Int J Med Robot 6:18-27

32. Thali MJ, Yen K, Schweitzer W et al (2003) Virtopsy, a new imaging horizon in forensic pathology: virtual autopsy by postmortem multislice computed tomography (MSCT) and magnetic resonance imaging (MRI)-a feasibility study. J Forensic Sci 48:386-403

33. Le Blanc-Louvry I, Thureau S, Duval C et al (2013) Post-mortem computed tomography compared to forensic autopsy findings: a French experience. Eur Radiol 23:1829-1835

34. Ruder TD, Hatch GM, Ebert LC et al (2012) Whole Body Postmortem Magnetic Resonance Angiography. J Forensic Sci 57:778-782

35. http://handbook.cochrane.org/ - accessed on the 17th of July, 2013.
36. Liberati A, Altman DG, Tetzlaff J, et al. (2009) The PRISMA Statement for Reporting Systematic Reviews and Meta-Analyses of Studies That Evaluate Health Care Interventions: Explanation and Elaboration. Plos Medicine, 6. doi: 10.1371/journal.pmed. 1000100

37. Roberts ISD, Benamore RE, Benbow EW et al (2012) Post-mortem imaging as an alternative to autopsy in the diagnosis of adult deaths: A validation study. Lancet 379:136-142

38. Takahashi N, Higuchi T, Shiotani M et al (2012) The effectiveness of postmortem multidetector computed tomography in the detection of fatal findings related to cause of non-traumatic death in the emergency department. Eur Radiol 22:152-160

39. Westphal SE, Apitzsch J, Penzkofer T, Mahnken AH, Knuchel R (2012) Virtual CT autopsy in clinical pathology: Feasibility in clinical autopsies. Virchows Arch 461:211-219

40. Farina J, Millana C, Fdez-Acenero JM et al (2002) Ultrasonographic autopsy (echopsy): A new autopsy technique. Virchows Arch 440:635-639

41. Farina J, Millana C (1998) Applications of ultrasonography on the post-mortem examination (ecopsy) in humans. J Echogr Med Ultrasons 19:280-286

42. Huston BM, Malouf NN, Azar HA (1996) Percutaneous needle autopsy sampling. MOD PATHOL 9:1101-1107

43. Ross SG, Thali MJ, Bolliger S, Germerott T, Ruder TD, Flach PM (2012) Sudden death after chest pain: Feasibility of virtual autopsy with postmortem CT angiography and biopsy. Radiology 264:250 259

44. Bolliger SA, Filograna L, Spendlove D, Thali MJ, Dirnhofer S, Ross S (2010) Postmortem imaging-guided biopsy as an adjuvant to minimally invasive autopsy with $\mathrm{CT}$ and postmortem angiography: A feasibility study. Am J Roentgenol 195:1051-1056

45. Puranik RGB, Lackey H, Yeates L, Parker G, Duflou J, Semsarian C (2014) Comparison of conventional autopsy and magnetic resonance imaging in determining the cause of sudden death in the young. J Cardiovasc Magn Reson 16:44

46. Wichmann D, Obbelode F, Vogel H et al (2012) Virtual autopsy as an alternative to traditional medical autopsy in the intensive care unit; A prospective cohort study. Ann Intern Med 156:123-130

47. Roberts ISD, Benbow EW, Bisset R et al (2003) Accuracy of magnetic resonance imaging in determining cause of sudden death in adults: Comparison with conventional autopsy. Histopathology 42: 424-430

48. Patriquin L, Kassarjian A, O'Brien M, Andry C, Eustace S (2001) Postmortem whole-body magnetic resonance imaging as an adjunct to autopsy: Preliminary clinical experience. J Magn Reson Imaging $13: 277-287$

49. Wichmann D, Heinemann A, Weinberg C et al (2014) Virtual Autopsy With Multiphase Postmortem Computed Tomographic Angiography Versus Traditional Medical Autopsy to Investigate Unexpected Deaths of Hospitalized Patients. Ann Intern Med 160:534

50. Weustink AC, Hunink MGM, Van Dijke CF, Renken NS, Krestin GP, Oosterhuis JW (2009) Minimally invasive autopsy: An alternative to conventional autopsy? Radiology 250:897-904

51. Fan JKM, Tong DKH, Poon JTC et al (2010) Multimodality minimally invasive autopsy-A feasible and accurate approach to postmortem examination. Forensic Sci Int 195:93-98

52. Cacchione RN, Sayad P, Pecoraro AM, Ferzli GS (2001) Laparoscopic autopsies. Surg Endosc 15:619-622

53. Thayyil S, Chandrasekaran M, Chitty LS et al (2010) Diagnostic accuracy of post-mortem magnetic resonance imaging in fetuses, children and adults: a systematic review. Eur J Radiol 75:e142e148

54. Bolliger SA, Thali MJ, Ross S, Buck U, Naether S, Vock P (2008) Virtual autopsy using imaging: bridging radiologic and forensic 
sciences. A review of the Virtopsy and similar projects. Eur Radiol 18:273-282

55. Flach PM, Thali MJ, Germerott T (2014) Times have changed! Forensic radiology-a new challenge for radiology and forensic pathology. AJR Am J Roentgenol 202:W325-W334

56. Avrahami R, Watemberg S, Daniels-Philips E, Kahana T, Hiss J (1995) Endoscopic autopsy. Am J Forensic Med Pathol 16:147150

57. Saunders SL, Morgan B, Raj V, Rutty GN (2011) Post-mortem computed tomography angiography: Past, present and future. Forensic Sci Med Pathol 7:271-277

58. Roberts ISD, Benamore RE, Peebles C, Roobottomd C, Traill ZC (2011) Diagnosis of coronary artery disease using minimally invasive autopsy: evaluation of a novel method of post-mortem coronary CT angiography. Clin Radiol 66:645-650

59. Saunders SL, Morgan B, Raj V, Robinson CE, Rutty GN (2011) Targeted post-mortem computed tomography cardiac angiography: proof of concept. Int J Legal Med 125:609-616

60. Germerott T, Preiss US, Ebert LC et al (2010) A new approach in virtopsy: Postmortem ventilation in multislice computed tomography. Leg Med (Tokyo) 12:276-279

61. Robinson C, Biggs MJ, Amoroso J, Pakkal M, Morgan B, Rutty GN (2014) Post-mortem computed tomography ventilation; simulating breath holding. Int J Legal Med 128:139-146

62. Rutty GN, Biggs MJP, Brough A et al (2015) Ventilated postmortem computed tomography through the use of a definitive airway. Int J Legal Med 129:325-334
63. Christe A, Ross S, Oesterhelweg L et al (2009) Abdominal TraumaSensitivity and Specificity of Postmortem Noncontrast Imaging Findings Compared With Autopsy Findings. J Trauma-Inj Infect Crit Care 66:1302-1307

64. Burton JL, Rutty GN The Hospital Autopsy: A Manual of Fundamental Autopsy Practice (Hodder Arnold Publication). CRC Press; 3 edition (25 Jun 2010).

65. Michaud K, Grabherr S, Jackowski C, Bollmann MD, Doenz F, Mangin P (2013) Postmortem imaging of sudden cardiac death. Int J Legal Med. doi:10.1007/s00414-013-0819-6

66. Jackowski C, Schweitzer W, Thali M et al (2005) Virtopsy: Postmortem imaging of the human heart in situ using MSCT and MRI. Forensic Sci Int 149:11-23

67. Bruguier C, Mosimann PJ, Vaucher P et al (2013) Multi-phase postmortem CT angiography: recognizing technique-related artefacts and pitfalls. Int J Legal Med 127:639-652

68. Fryer EP, Traill ZC, Benamore RE, Roberts IS (2013) High risk medicolegal autopsies: is a full postmortem examination necessary? J Clin Pathol 66:1-7

69. van der Linden A, Blokker BM, Kap M, Weustink AC, Riegman PH, Oosterhuis JW (2014) Post-Mortem Tissue Biopsies Obtained at Minimally Invasive Autopsy: An RNA-Quality Analysis. PLoS One 9, e115675. doi:10.1371/journal.pone.0115675

70. Ebert LC, Ptacek W, Furst M, Ross S, Thali MJ, Hatch G (2012) Minimally invasive postmortem telebiopsy. J Forensic Sci 57:528-530

71. Lundstrom C, Persson A, Ross S et al (2012) State-of-the-art of visualization in post-mortem imaging. Apmis 120:316-326 